\title{
Mesoscopic Characteristics on Cracks of Three-Point Bending RC Beam with Corroded Reinforcement
}

\author{
Nan Wu, ${ }^{1,2}$ Hao Jin $\mathbb{D}^{3}{ }^{3}$ Qingrong Tian, ${ }^{4}$ and Zheng $\mathrm{Li}^{4}$ \\ ${ }^{1}$ Kunshan Rail Transit Investment \& Properties Co., Ltd., 215332 Kunshan, China \\ ${ }^{2}$ Kunshan Rail Transit Investment and Development Co., Ltd., 215332 Kunshan, China \\ ${ }^{3}$ School of Transportation, Southeast University, Nanjing 211189, China \\ ${ }^{4}$ The Key Laboratory of Road and Traffic Engineering, Ministry of Education, Tongji University, Shanghai 201804, China \\ Correspondence should be addressed to Hao Jin; jinhao@seu.edu.cn
}

Received 17 November 2019; Revised 3 November 2020; Accepted 26 November 2020; Published 16 December 2020

Academic Editor: Wayne Yu Wang

Copyright $\odot 2020 \mathrm{Nan}$ Wu et al. This is an open access article distributed under the Creative Commons Attribution License, which permits unrestricted use, distribution, and reproduction in any medium, provided the original work is properly cited.

\begin{abstract}
The RC beam usually works under the combined action of external loads and corrosion expansion pressures, and the RC beams without corrosion of reinforcements have good mechanical performance. In this study, the mesoscopic models of the three-point bending RC beams with different aggregates, different aggregate contents, and different corrosion expansion pressures were built. The plastic strain and the deflection are analyzed. The results show that the cracks of the RC beam with polygon aggregates are more dispersed than circle aggregates. As the aggregate content increases, the maximum plastic strain and maximum deflection of the RC beam decrease. The aggregate contents increased from $25 \%$ to $35 \%$, the maximum plastic strain decreased from $3.4 \times 10^{-3}$ to $2.1 \times 10^{-3}$, and the maximum deflection of the lower boundary of the beam decreased from $0.005 \mathrm{~m}$ to $0.004 \mathrm{~m}$. Furthermore, the corrosion expansion pressure makes the plastic strain increase in the concrete cover.
\end{abstract}

\section{Introductions}

Corrosion-induced crack is the primary cause of the bearing-capacity degradation of RC beams [1,2]. Reinforcement corrosion not only reduces the bonding performance between reinforcement and concrete [3-8], but also causes concrete cracking and even spalling of concrete cover [9-11]. In addition, RC beams are often subjected to external loads. Under the combined action of reinforcement corrosion and external loads, cracks in concrete will grow faster, which will result in structure performance degradation [12-14]. Therefore, it is very significant to analyze this problem.

In the past two decades, a tremendous amount of work has been carried out to investigate the cracking behavior of $\mathrm{RC}$ beams under loads and reinforcement corrosion by using experimental methods and numerical methods. In experimental studies, the galvanic method and artificial climate exposure method are used to study the crack characteristics and mechanical performance for the corroded RC beams under sustained loading $[5,15-21]$. The crack-propagation behaviors of the RC beams under different loading levels and corrosion levels were described [15-18], and the deflection variation is compared in the test $[5,19-21]$. The work of concrete cracking under the coupled effect of sustained loading and corrosion is quite extensive.

Comparing with the experimental study, the numerical calculation is an effective tool to analyze the internal cracking mechanism of RC beams. Chernin and Val [22] combined numerical calculation and experimental verification and discussed the initial cracking time of RC beams. A simple nonlinear finite element (FE) is then formulated and validated for predicting the time to corrosion-induced cover cracking. Zhu and $\mathrm{Zi}$ [23] developed a two-dimensional model that coupled with ingress of chloride ions, carbonation, electrochemical reaction, and corrosion-induced mechanical damage and studied the expansive pressure and the growth of corrosion-induced cracks of RC beams. Using the model, they can predict the nonuniform distribution of the corrosion product, the expansive pressure, and the growth of corrosion-induced cracks. Ožbolt et al. [24] built a 
three-dimensional model that coupled with chemo-hygrothermo-mechanical for predicting crack patterns due to corrosion-induced damage. The comparison between numerical results and experimental evidence shows that the model is able to realistically predict experimentally observed crack pattern. However, all these efforts have been carried out based on the assumption that concrete is a homogeneous medium and the effect of external loads is not considered.

In reality, the mechanical behaviors of concrete, for instance, the macroscopic mechanical properties and the failure pattern, are closely associated with the microstructure of concrete. In the numerical simulation, the heterogeneity of concrete should be considered [25-31]. Therefore, Pacheco et al. [32] used the mesoscale lattice model to study the radial expansion behavior of concrete. Du and Jin [33] assumed that the concrete is a three-phase composite composed of circular aggregate, mortar matrix, and the interfacial transition zone (ITZ) and studied the crack pattern of microconcrete components in the direction of cross section. The present work is just an attempt to study the mesoscale cracking behavior in concrete cover. There are still some efforts that need to be further discussed [33].

Therefore, the mesoscale characteristic of the corroded RC beam due to external load will be studied in this paper and the plastic strain crack and the deflection of the RC beam will be analyzed. This paper is organized as follows. Section 2 will introduce the method of building the mesoscale concrete model. A 2D model of three-point bending RC beam will be built in Section 3. Sections 4, 5, and 6 will analyze the effect of the aggregate shape, the aggregate content, and the corrosion expansion pressure. Conclusions are given in Section 7 .

\section{Building Method of the Mesoscale Concrete Model}

2.1. Aggregate Generation. For real aggregates, the outline shapes are very complex. In this paper, a hand-held laser scanner was used to scan the real aggregate for the $3 \mathrm{D}$ outline shapes. For the 2D aggregate model, the original contour points of the reconstructed aggregate will make the meshing and calculation in the finite element model highly complex. Therefore, it is necessary to simplify the original contour points.

The key control points can be extracted from the original contour points [34], such as given in Figure 1. These key control points can describe the basic outline shape of the real aggregate using as few as possible contour points, named the aggregate base of the real aggregate.

2.2. Aggregate Placement. In this study, we propose an aggregate placement algorithm based on the intrusion judgment of front polygons-rear circumcircle. The algorithm is proposed as follows. Determine the circumcircles of each aggregate in the real aggregate library and then place the aggregates from large to small according to gradation. When placing a new aggregate, determine if the new aggregate circumcircle and the placed aggregate contours overlap. The algorithm of aggregate placement effectively solves the problem of low discriminating efficiency between polygons with significant numbers of control points while simultaneously satisfying the gradation variation of the aggregates without creating large gaps between the aggregates [34]. The average particle size range of aggregate is $3 \mathrm{~mm}-16 \mathrm{~mm}$. Aggregate placement is shown in Figure 2.

2.3. Aggregate Overlap Criteria. An aggregate placement process is complete when the circumcircle of the aggregate is placed into the designated area. Therefore, it is necessary to judge whether the circumcircles of the existing aggregates and the new aggregate overlap when placing, and this can be regarded as the intrusion relationship between polygons and circles. The method simplifies the judgment required between traditional polygons. Simultaneously, the principle of placing aggregates from large to small circumvents the problem of low aggregate content because of gaps between the circumscribed circles and the polygons.

When judging the location of the relationship between circles and polygons, it can be divided into three cases: (1) control point inside the circle, (2) polygonal edges intersect with circles, and (3) circle inside the polygon. For the first case, it can be immediately determined if the aggregate control point is inside the circumcircle. For the second case, it is required to judge whether the distance from the circumcircle center to the straight line is smaller than the circumcircle radius and whether the vertical point falls on the line segment formed by the adjacent control point; we call it criterion A. For the third case, calculate each angle between the circumcircle center and two adjacent vertices and then determine if the sum of these angles is equal to $360^{\circ}$; we call it criterion $\mathrm{B}$. The flowchart of the judgment criterion is shown in Figure 3.

\section{Mesoscale Model of Three-Point Bending RC Beam}

3.1. Sizes of the RC Beam. Considering the calculation time and efficiency of the mesoscale concrete model, the length of the RC beam is $300 \mathrm{~mm}$ and the height is $50 \mathrm{~mm}$. The thickness of the concrete cover is $7.5 \mathrm{~mm}$. The diameter of the steel bar is $4 \mathrm{~mm}$. The length of the steel bar is $275 \mathrm{~mm}$. The two ends of the steel bar are $12.5 \mathrm{~mm}$ from each end of the $\mathrm{RC}$ beam, as shown in Figure 4. The concrete does not include the aggregates, aggregate shrinkage within $0.5 \mathrm{~mm}$ is used as the interface between the aggregate and mortar, and the interface constitutive adopts the plastic damage constitutive.

3.2. Constitutive Relation. The mesoscale concrete model will be calculated using ABAQUS. The damage plasticity model $[35,36]$ is always used to describe the fracture behavior of concrete materials. In this paper, the evolution model of the double-fold damage variable is adopted as the constitutive of the aggregate, the mortar, and the interface, as shown in Figure 5. 


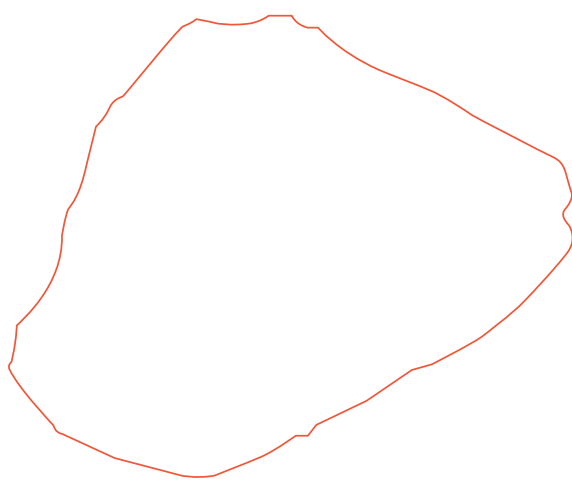

(a)

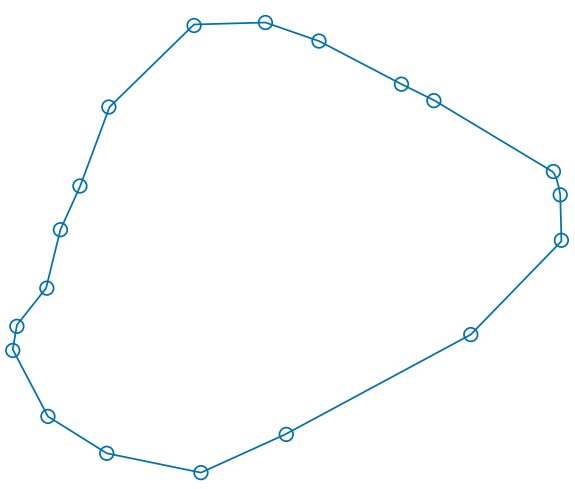

(b)

Figure 1: Contour points' simplification. (a) Original contour points and (b) key control points.

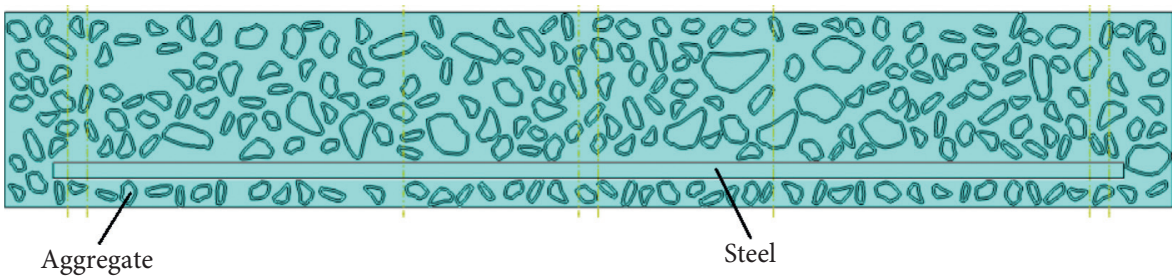

Figure 2: Aggregate placement.

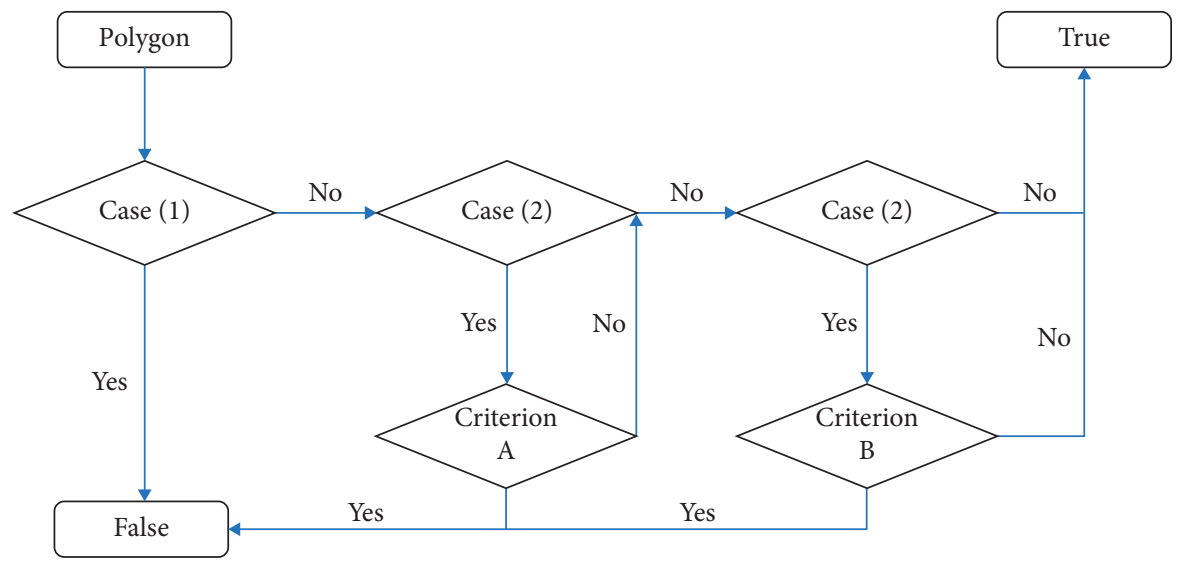

FIgURE 3: Flowchart of the judgment criterion.

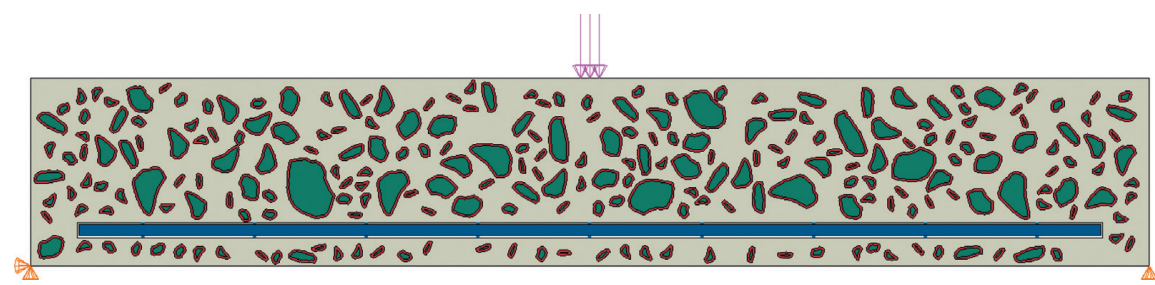

Figure 4: The three-point bending RC beam. 


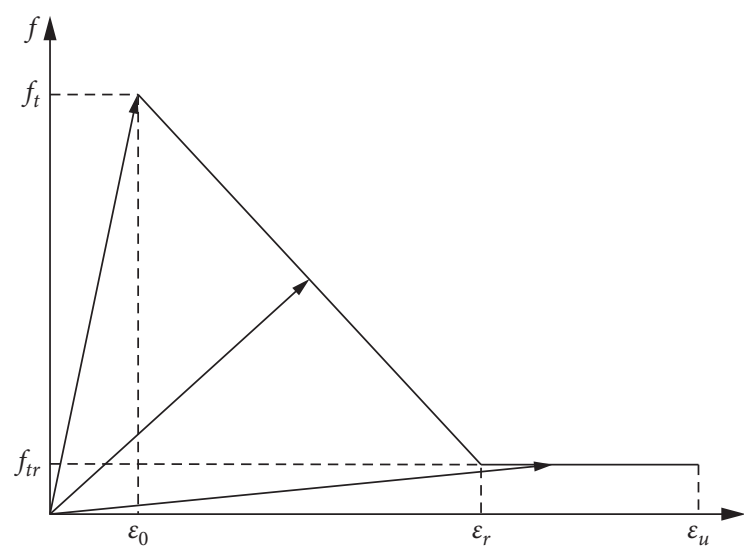

Figure 5: Double-fold line damage constitutive relation, where $f_{t}$ is the tensile strength, $f_{t r}$ is the residual tensile strength, $\varepsilon_{0}$ is the principal tensile strain corresponding to $f_{t}, \varepsilon_{r}$ is the residual strain corresponding to the tensile residual strength $f_{t r}$, and $\varepsilon_{u}$ is the ultimate tensile strain.

The damage variables can be expressed as

$$
D= \begin{cases}0, & \varepsilon_{\max }<\varepsilon_{0}, \\ 1-\frac{\eta-\lambda}{\eta-1} \frac{\varepsilon_{0}}{\varepsilon_{\max }}+\frac{1-\lambda}{\eta-1}, & \varepsilon_{0}<\varepsilon_{\max } \leq \varepsilon_{r}, \\ 1-\lambda \frac{\varepsilon_{0}}{\varepsilon_{\max }}, & \varepsilon_{r}<\varepsilon_{\max } \leq \varepsilon_{u}, \\ 1, & \varepsilon_{\max }>\varepsilon_{u},\end{cases}
$$

where $\varepsilon_{\max }$ is the largest primary tensile strain value of the loading history. The relationship between parameters is $f_{t r}=\lambda f_{r}(0<\lambda<1), \varepsilon_{r}=\varepsilon_{0}$, and $\varepsilon_{u}=\xi \varepsilon_{0}(\xi>\eta)$.

The elastic modulus of the aggregate is $50 \mathrm{GPa}$ [37], tensile strength is $6 \mathrm{MPa}$, Poisson's ratio is $0.2, \lambda$ is $0.1, \eta$ is 10 , and $\xi$ is 5 . The elastic modulus of the mortar is $26 \mathrm{GPa}$, tensile strength is $3.2 \mathrm{MPa}$, Poisson's ratio is $0.2, \lambda$ is $0.1, \eta$ is 10 , and $\xi$ is 4 . The elastic modulus of the interface is $25 \mathrm{GPa}$, tensile strength is $3 \mathrm{MPa}$, Poisson's ratio is $0.2, \lambda$ is $0.1, \eta$ is 10 , and $\xi$ is 4 .

3.3. Simulation of Interaction between Steel Bar and Concrete. While formulating the rust expansion model, the following basic assumptions are made [38]: (1) the corrosion process is spatially uniform around the steel reinforcement which results in a uniform radial expansive pressure at the steel- concrete interface; (2) the concrete around the steel reinforcing bar is modeled as a thick-walled cylinder, and the wall thickness equals to the thinnest concrete cover.

In the initial stage of steel corrosion, the rust layer will fill the gap between steel and concrete, the gap layer thickness is $\varepsilon_{0}$, as shown in Figure 6 . With the accumulation of rust layer, the rust expansion pressure will cause compressive deformation of the concrete; the deformation thickness of the concrete is $\varepsilon_{c}$. In Figure 6, the diameter of steel bar is indicated by $D$, the combined diameter of noncorroded steel plus free-expansive corrosion products is indicated by $D_{f}$, the radial loss of steel is $\varepsilon_{s}$, the diameter of noncorroded steel bar $D_{n}=D-2 \varepsilon_{s}$, and the corresponding radial displacement is indicated by $\varepsilon_{r}$.

When $R_{1}=D / 2+\varepsilon_{0}$ and $R_{2}=D_{f} / 2$, the deformation compatibility equation at steel-concrete interface is given by

$$
R_{1}+\varepsilon_{c}=R_{2}-\varepsilon_{r} .
$$

The displacements of the concrete and corrosion products are defined as follows [39]:

$$
\begin{aligned}
\mathcal{E}_{c} & =\frac{R_{1}}{E_{\mathrm{cef}}}\left[\frac{\left(R_{1}+c\right)+R_{1}^{2}}{\left(R_{1}+c\right)-R_{1}^{2}}+v_{c}\right] \cdot Q_{r}, \\
\varepsilon_{r} & =\frac{R_{2}}{E_{r}} \cdot \frac{\left(1-v_{r}^{2}\left(R_{2}^{2}-D_{n}^{2}\right) / 4\right)}{\left(1-v_{r}\right)\left(D_{n}^{2} / 4\right)+\left(1+v_{r}\right) R_{2}^{2}} \cdot Q_{r},
\end{aligned}
$$

where $E_{\text {cef }}$ is the effective elastic modulus of the concrete with $E_{\text {cef }}=E_{c} /(1+\zeta)$, in which $\zeta$ is the creep coefficient of the concrete [40], $v_{c}$ is Poisson's ratio of the concrete, and $E_{r}$ and $v_{r}$ are elastic modulus and Poisson's ratio of the corrosion products, respectively.

The relationship between corrosion rate $\rho$ and parameter of $D_{n}$ with $D_{f}$ is given as follows:

$$
\begin{aligned}
\rho & =\frac{M_{l}}{M_{t}}=1-\left(\frac{D_{n}}{D}\right)^{2}, \\
D_{n} & =D \sqrt{1-\rho}, \\
D_{f} & =2 R_{2}=D \sqrt{1+(n-1) \rho},
\end{aligned}
$$

where $n$ is the ratio of volume expansion of corrosion products, $M_{t}$ is the total mass of steel, and $M_{l}$ is corrosion loss mass of steel.

Then, from equation (2) using the relationship given in equations (3)-(7), the relationship between the radial pressure $Q_{r}$ and the corrosion rate $\rho$ can be expressed as

$$
Q_{r}=\frac{\sqrt{1+(n-1) \rho}-1-2 \varepsilon_{0} / D}{\left.1 / E_{\text {cef }}\left[\left(\left(D / 2+\varepsilon_{0}+c\right)^{2}+\left(D / 2+\varepsilon_{0}\right)^{2}\right) /\left(\left(D / 2+\varepsilon_{0}+c\right)^{2}-\left(D / 2+\varepsilon_{0}\right)^{2}\right)\right)+v_{c}\right]+\left(1 / E_{\text {cef }}\right)\left(n \rho\left(1-v_{r}^{2}\right) \sqrt{1+(n-1) \rho} /\left[\left(1+v_{r}\right) n-2\right] \rho+2\right)} .
$$

Concrete cracking is affected by the corrosion of internal steel bar [41]. Furthermore, in view of the bonding slip between the steel bar and the concrete, the tangential springs are set per $30 \mathrm{~mm}$ along the length direction of the steel bar [42], as shown in Figure 7. 


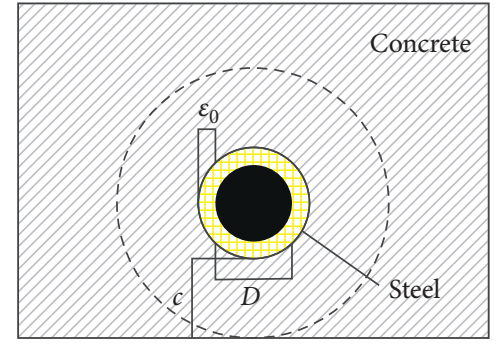

(a)

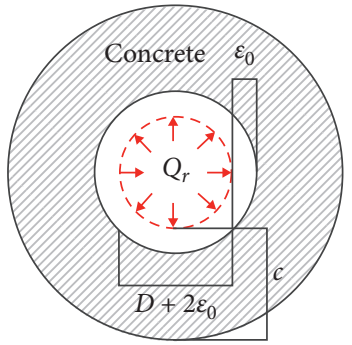

(b)

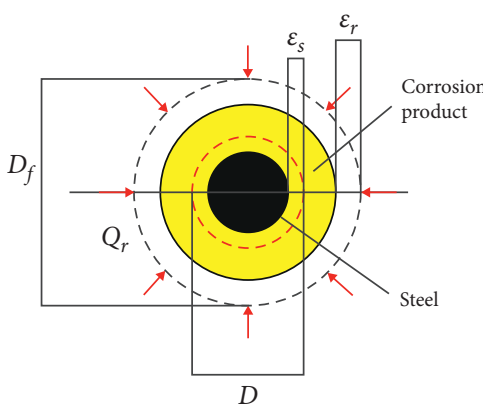

(c)

Figure 6: Thick-walled cylinder model. (a) Initial RC structure, (b) concrete deformation, and (c) deformation of corrosion products.

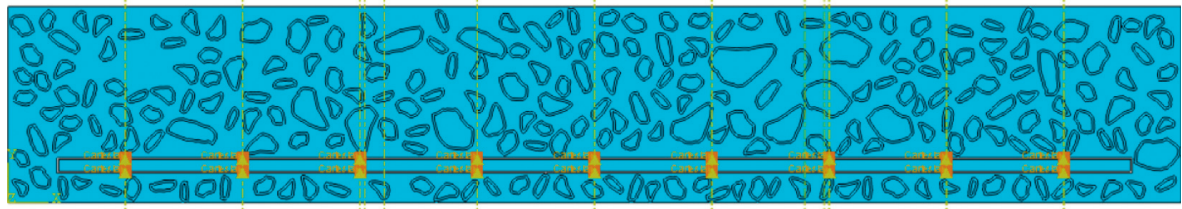

FIgURE 7: Tangential spring setting.

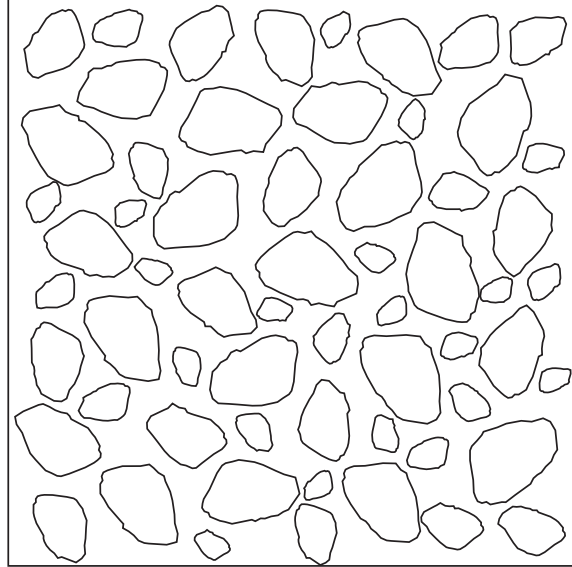

(a)

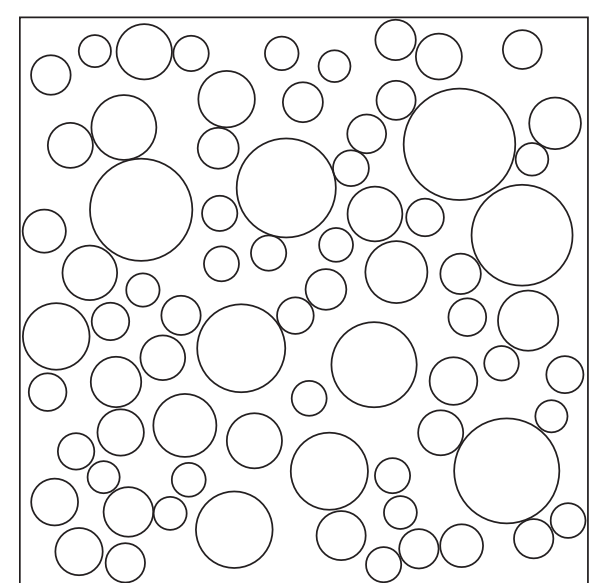

(b)

FIGURE 8: Different aggregates: (a) polygon aggregates and (b) circle aggregates.

3.4. Boundary and Load Conditions. The left boundary is the vertical constraint and the horizontal constraint. The right boundary is the vertical constraint. The upper middle of the RC beam is loaded, as shown in Figure 4. The pressure applied to the top of the beam is $5 \mathrm{MPa}$. The number of elements is 111265 .

\section{RC Beam with Different Aggregates}

Two kinds of aggregates are analyzed. The first one is the polygon aggregate based on the laser scan of the real aggregate, as shown in Figure 8(a). The second one is the circular aggregate, as shown in Figure 8(b). The plastic strain of the $\mathrm{RC}$ beam and the deflection curve of the RC beam under the external load are analyzed, respectively.

Figure 9 shows the plastic strain of the three-point bending RC beam with two different aggregates. Both of the aggregates' content is 35\%. Comparing Figure 9(a) with Figure 9(b), the maximum plastic strain of the RC beam with the circular aggregate is greater than the polygon aggregate. Because of the complex outline shapes of the real aggregates, the plastic strain cracks [42] of the RC beam are more irregular. It makes the plastic strain cracks more dispersed. In contrast, the plastic strain cracks of the RC beam with the circular aggregates are almost arc. It makes the plastic strain cracks more concentrated. In addition, there are some plastic 


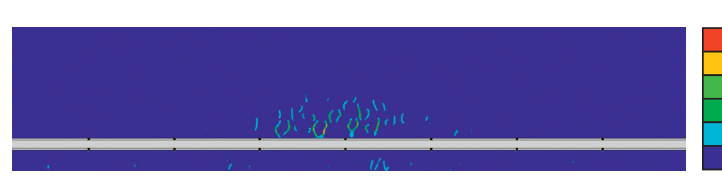

(a)

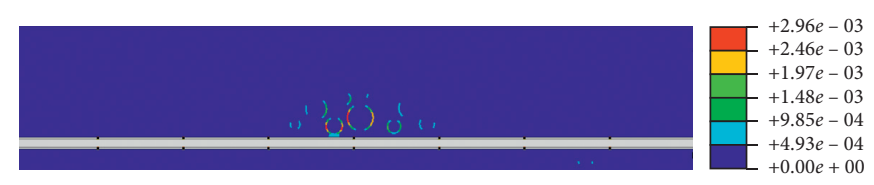

(b)

FIGURE 9: RC beam with different aggregate shapes: (a) polygon aggregate shapes and (b) circle aggregate shapes.

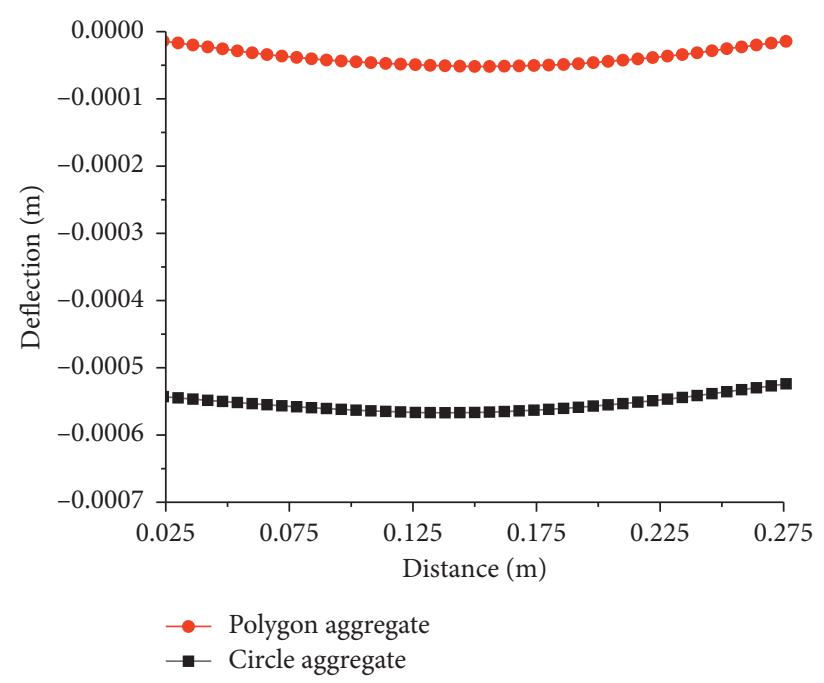

Figure 10: Deflection of the lower boundary of the RC beam.

strain cracks in the concrete cover of the RC beam using the polygon aggregates.

Figure 10 shows the deflection curve of the lower boundary of the RC beam. The vertical displacement of the lower boundary of the RC beam with the circular aggregates is much larger than the polygon aggregates. It implies that the RC beam with the polygon aggregate has better flexural rigidity.

Therefore, we can infer that the RC beam with the circular aggregate is more likely to form a penetrating large crack in the subsequent force process. In the following section, only the polygon aggregate is analyzed.

\section{RC Beam with Different Aggregate Contents}

There are three kinds of aggregate contents, $25 \%, 30 \%$, and $35 \%$, in this section. The plastic strain cracks of the RC beam are analyzed, as shown in Figure 11. The maximum plastic strain of the RC beam with $25 \%$ aggregate content is the largest among these three aggregate contents. With the increase in aggregate contents, the maximum plastic strain decreases. In addition, Figure 11 shows that the more aggregate content, the more dispersed the plastic strain cracks. It reflects that more aggregate content will make the RC beam have better flexural rigidity. The output is PE in Figures 11 and 12.

\section{RC Beam with Different Corrosion Expansion Pressures}

According to equation (8), the ultimate corrosion expansion pressure is calculated as $2.69 \mathrm{MPa}$. In this section, three different corrosion expansion pressures, $2 \%$ ultimate corrosion expansion pressure, $3 \%$ ultimate corrosion expansion pressure, and 3.5\% ultimate corrosion expansion pressure, are analyzed.

Figure 12 shows the plastic strain cracks of the RC beam with $25 \%$ aggregate content under different corrosion expansion pressures. With the increase in the corrosion expansion pressure, the maximum plastic strain increases. The development of plastic strain is mainly in the concrete cover. Comparing Figures 11(a) and 12(a), it is obvious that the corrosion expansion pressure causes the large area of the plastic strain cracks in the concrete cover. The RC beam with $30 \%$ aggregate content and the RC beam with $35 \%$ aggregate content under different corrosion expansion pressures have the same pattern as Figure 12.

Figure 13(a) shows the deflection of the upper boundary and the lower boundary of the RC beam with no corrosion. From Figure 13(a), the deflection of the upper boundary is a little greater than the lower boundary. This is due to the larger elastic modulus of the steel bar than the concrete materials. In order to satisfy displacement coordination, the concrete deformation is constrained by the steel bar. Therefore, the vertical displacement of the lower boundary is smaller than the upper boundary.

Figure 13(b) shows the deflection of the upper boundary and the lower boundary of the RC beam with $2 \%$ ultimate corrosion expansion pressure. From Figure 13(b), the vertical displacement of the lower boundary is much greater than the upper boundary. This is different from the results shown in Figure 13(a). The reason for this phenomenon is 


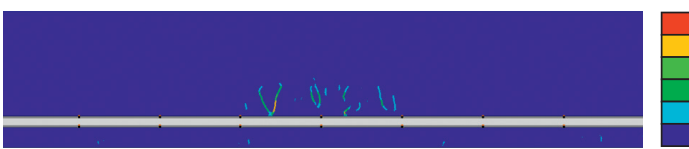

(a)

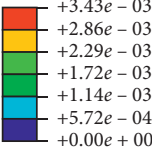

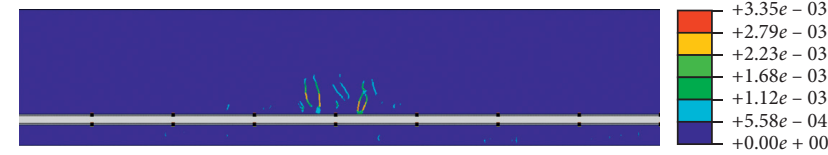

(b)

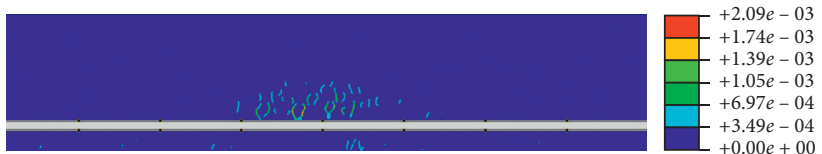

(c)

FIGURE 11: RC beam with different aggregate contents: (a) 25\%, (b) 30\%, and (c) $35 \%$.

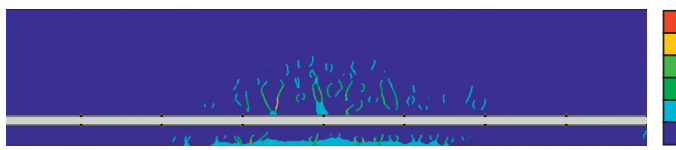

(a)

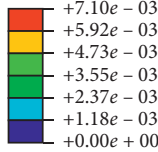

$+0.00 e+00$

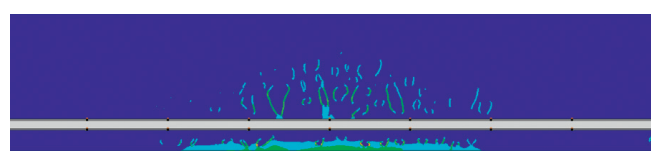

(c)

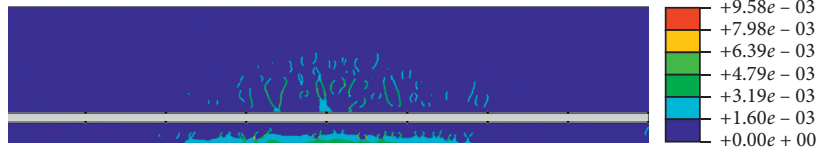

(b)

FiguRE 12: RC beam under different corrosion expansion pressures with $25 \%$ aggregate content: (a) $2 \%$, (b) $3 \%$, and (c) $3.5 \%$.

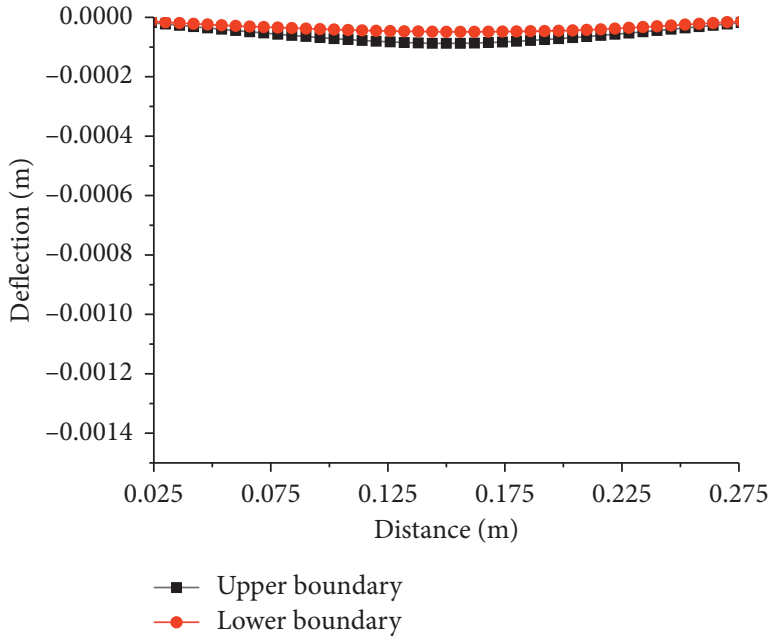

(a)

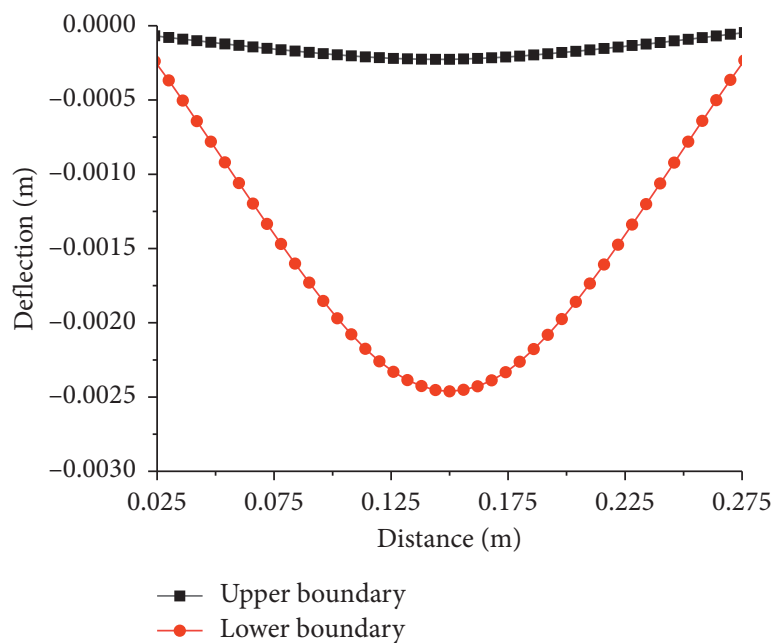

(b)

Figure 13: Deflection of the RC beam with different corrosion expansion pressures: (a) no corrosion and (b) $2 \%$ corrosion expansion pressure.

that corrosion expansion pressure is applied directly on the concrete cover. It makes the vertical displacement of the concrete cover increase rapidly. This result can be explained in mesoscale through Figures 11 and 12.

Figure 14 shows the deflection of the lower boundary of the RC beam with different aggregate contents under different corrosion expansion pressures. It is obvious that, with the increase in the corrosion expansion pressure, the vertical displacement of the lower boundary of the RC beam increases. In addition, the displacement of the lower boundary of the RC beam with $35 \%$ aggregate content is the smallest among these three aggregate contents. 


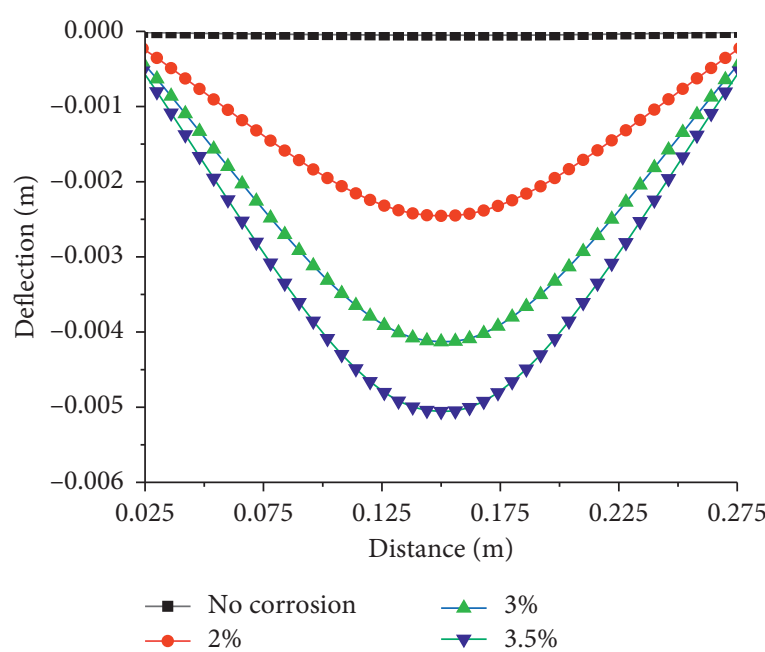

(a)

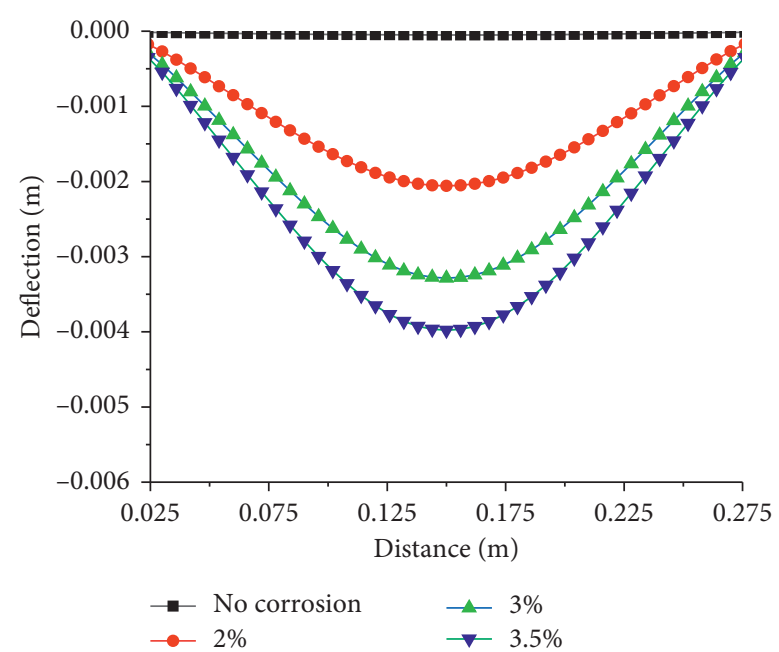

(b)

FIGURE 14: Deflection of the RC beam with different aggregate contents under different corrosion expansion pressures: (a) 25\% and (b) $35 \%$.

\section{Conclusions}

Based on the mesoscale concrete model, the three-point bending RC beams with different aggregate shapes, different aggregate contents, and different corrosion expansion pressures are simulated. The plastic strain crack and the deflection of the RC beam are analyzed. According to the numerical calculation, the conclusions are drawn as follows:

(1) The plastic strain cracks of the RC beam with the polygon aggregates are more dispersed than the circle aggregates. It presents that the $\mathrm{RC}$ beam with the polygon aggregate has better flexural rigidity.

(2) As the aggregate content increases, the maximum plastic strain and maximum deflection of the RC beam decrease. The aggregate contents increased from $25 \%$ to $35 \%$, the maximum plastic strain decreased from $3.4 \times 10^{-3}$ to $2.1 \times 10^{-3}$, and the maximum deflection of the lower boundary of the beam decreased from $0.005 \mathrm{~m}$ to $0.004 \mathrm{~m}$.

(3) The corrosion expansion pressure makes the plastic strain increase in the concrete cover. With the increase in the corrosion expansion pressure, the deflection of the lower boundary of the beam will increase, which will lead to the peeling of the concrete cover.

\section{Data Availability}

Data will be made available on request.

\section{Conflicts of Interest}

The authors declare that they have no conflicts of interest.

\section{Acknowledgments}

This study was sponsored by the National Nature Science Foundation of China (Grant no. 51908428) and the Natural Science Foundation of Shanghai (Grant no. 19ZR1460400).

\section{References}

[1] C. Fu, N. Jin, H. Ye, X. Jin, and W. Dai, "Corrosion characteristics of a 4-year naturally corroded reinforced concrete beam with load-induced transverse cracks," Corrosion Science, vol. 117, pp. 11-23, 2017.

[2] G. Malumbela, M. Alexander, and P. Moyo, "Variation of steel loss and its effect on the ultimate flexural capacity of RC beams corroded and repaired under load," Construction and Building Materials, vol. 24, no. 6, pp. 1051-1059, 2010.

[3] H. Lin and Y. Zhao, "Effects of confinements on the bond strength between concrete and corroded steel bars," Construction and Building Materials, vol. 118, pp. 127-138, 2016.

[4] A. A. Almusallam, A. S. Al-Gahtani, A. R. Aziz, and Rasheeduzzafar, "Effect of reinforcement corrosion on bond strength," Construction and Building Materials, vol. 10, no. 2, pp. 123-129, 1996.

[5] Y. Du, M. Cullen, and C. Li, "Structural effects of simultaneous loading and reinforcement corrosion on performance of concrete beams," Construction and Building Materials, vol. 39, pp. 148-152, 2013.

[6] F. Tondolo, "Bond behaviour with reinforcement corrosion," Construction and Building Materials, vol. 93, pp. 926-932, 2015.

[7] M. Blomfors, K. Zandi, K. Lundgren, and D. Coronelli, "Engineering bond model for corroded reinforcement," Engineering Structures, vol. 156, pp. 394-410, 2018.

[8] Y.-Z. Wu, H.-L. Lv, S.-C. Zhou, and Z.-N. Fang, "Degradation model of bond performance between deteriorated concrete and corroded deformed steel bars," Construction and Building Materials, vol. 119, pp. 89-95, 2016.

[9] D. V. Val and L. Chernin, "Cover cracking in reinforced concrete elements due to corrosion," Structure and Infrastructure Engineering, vol. 8, no. 6, pp. 569-581, 2012.

[10] L. Chernin, D. V. Val, and K. Y. Volokh, "Analytical modelling of concrete cover cracking caused by corrosion of reinforcement," Materials and Structures, vol. 43, no. 4, pp. 543-556, 2010.

[11] K. Bhargava, A. K. Ghosh, Y. Mori, and S. Ramanujam, "Model for cover cracking due to rebar corrosion in RC structures," Engineering Structures, vol. 28, no. 8, pp. 1093-1109, 2006. 
[12] G. Malumbela, M. Alexander, and P. Moyo, "Lateral deformation of RC beams under simultaneous load and steel corrosion," Construction and Building Materials, vol. 24, no. 1, pp. 17-24, 2010.

[13] H. Li, B. Li, R. Jin, S. Li, and J.-G. Yu, "Effects of sustained loading and corrosion on the performance of reinforced concrete beams," Construction and Building Materials, vol. 169, pp. 179-187, 2018.

[14] G. Malumbela, M. Alexander, and P. Moyo, "Steel corrosion on RC structures under sustained service loads-a critical review," Engineering Structures, vol. 31, no. 11, pp. 2518-2525, 2009.

[15] J. Dong, Y. Zhao, K. Wang, and W. Jin, "Crack propagation and flexural behaviour of RC beams under simultaneous sustained loading and steel corrosion," Construction and Building Materials, vol. 151, pp. 208-219, 2017.

[16] L. Hariche, Y. Ballim, M. Bouhicha, and S. Kenai, "Effects of reinforcement configuration and sustained load on the behaviour of reinforced concrete beams affected by reinforcing steel corrosion," Cement and Concrete Composites, vol. 34, no. 10, pp. 1202-1209, 2012.

[17] L. Yu, R. François, V. H. Dang, V. L’Hostis, and R. Gagné, "Development of chloride-induced corrosion in pre-cracked RC beams under sustained loading: effect of load-induced cracks, concrete cover, and exposure conditions," Cement and Concrete Research, vol. 67, pp. 246-258, 2015.

[18] H. Ye, C. Fu, N. Jin, and X. Jin, "Performance of reinforced concrete beams corroded under sustained service loads: a comparative study of two accelerated corrosion techniques," Construction and Building Materials, vol. 162, pp. 286-297, 2018.

[19] S. Yoon, K. Wang, W. Weiss, and S. P. Shah, "Interaction between loading, corrosion and serviceability," ACI Structural Journal, vol. 97, no. 6, pp. 637-644, 2000.

[20] L. Yu, R. François, V. H. Dang, V. L'Hostis, and R. Gagné, "Structural performance of RC beams damaged by natural corrosion under sustained loading in a chloride environment," Engineering Structures, vol. 96, pp. 30-40, 2015.

[21] Y. Ballim and J. C. Reid, "Reinforcement corrosion and the deflection of RC beams-an experimental critique of current test methods," Cement and Concrete Composites, vol. 25, no. 6, pp. 625-632, 2003.

[22] L. Chernin and D. V. Val, "Prediction of corrosion-induced cover cracking in reinforced concrete structures," Construction and Building Materials, vol. 25, no. 4, pp. 1854-1869, 2011.

[23] X. Zhu and G. Zi, "A 2D mechano-chemical model for the simulation of reinforcement corrosion and concrete damage," Construction and Building Materials, vol. 137, pp. 330-344, 2017.

[24] J. Ožbolt, F. Oršanić, G. Balabanić, and M. Kušter, "Modeling damage in concrete caused by corrosion of reinforcement: coupled 3D FE model," International Journal of Fracture, vol. 178, no. 1-2, pp. 233-244, 2012.

[25] X. Wang, M. Zhang, and A. P. Jivkov, "Computational technology for analysis of 3D meso-structure effects on damage and failure of concrete," International Journal of Solids and Structures, vol. 80, pp. 310-333, 2016.

[26] S.-M. Kim and R. K. Abu Al-Rub, "Meso-scale computational modeling of the plastic-damage response of cementitious composites," Cement and Concrete Research, vol. 41, no. 3, pp. 339-358, 2011.

[27] S. Shahbazi and I. Rasoolan, "Meso-scale finite element modeling of non-homogeneous three-phase concrete," Case Studies in Construction Materials, vol. 6, pp. 29-42, 2017.
[28] X. Du, L. Jin, and G. Ma, "Numerical simulation of dynamic tensile-failure of concrete at meso-scale," International Journal of Impact Engineering, vol. 66, pp. 5-17, 2014.

[29] L. Design, A. Chen, Z. Pan, and R. Ma, "Mesoscopic simulation of steel rebar corrosion process in concrete and its damage to concrete cover," Structure and Infrastructure Engineering, vol. 13, no. 4, pp. 478-493, 2017.

[30] W. Ren, Z. Yang, R. Sharma, C. Zhang, and P. J. Withers, "Two-dimensional X-ray CT image based meso-scale fracture modelling of concrete," Engineering Fracture Mechanics, vol. 133, pp. 24-39, 2015.

[31] X. Xi, S. Yang, and C.-Q. Li, "A non-uniform corrosion model and meso-scale fracture modelling of concrete," Cement and Concrete Research, vol. 108, pp. 87-102, 2018.

[32] J. Pacheco, E. Schlangen, B. Šavija, and M. Lukovic, "Cracking of the concrete cover due to reinforcement corrosion: a twodimensional lattice model study," Construction and Building Materials, vol. 44, pp. 626-638, 2013.

[33] X. Du and L. Jin, "Meso-scale numerical investigation on cracking of cover concrete induced by corrosion of reinforcing steel," Engineering Failure Analysis, vol. 39, pp. 21-33, 2014.

[34] Y. Zhou, H. Jin, B. Wang, and S. Zhou, "Modeling and mechanical influence of meso-scale concrete considering actual aggregate shapes," Construction and Building Materials, vol. 228, Article ID 116785, 2019.

[35] H. Jin, K. Yu, Q. Gong, and S. Zhou, "Load-carrying capability of shield tunnel damaged by shield shell squeezing action during construction," Thin-Walled Structures, vol. 132, pp. 69-78, 2018.

[36] H. Jin, S. Yu, S. Zhou, and J. Xiao, "Research on mechanics of longitudinal joint in shield tunnel by the nonlinear spring equivalent method," KSCE Journal of Civil Engineering, vol. 23, no. 2, pp. 902-913, 2019.

[37] L. G. Sun, C. B. Du, and C. X. Dai, "Numerical simulation of random aggregate model for mass concrete," Journal of Hehai University (Natural Sciences), vol. 33, no. 3, Article ID 291295, 2005.

[38] C. Lu, W. Jin, and R. Liu, "Reinforcement corrosion-induced cover cracking and its time prediction for reinforced concrete structures," Corrosion Science, vol. 53, no. 4, pp. 1337-1347, 2011.

[39] T. El Maaddawy and K. Soudki, "A model for prediction of time from corrosion initiation to corrosion cracking," Cement and Concrete Composites, vol. 29, no. 3, pp. 168-175, 2007.

[40] W. G. Hime, L. A. Backus, and C. Q. Li, "Modeling time-tocorrosion cracking in chloride contaminated reinforced concrete structures. Discussions and closure," ACI Materials Journal, vol. 96, no. 6, 1999.

[41] H. Jin and S. Yu, "Effect of DC stray current on rebar corrosion in cracked segment of shield tunnel," Construction and Building Materials, Article ID 121646, 2020.

[42] O. Gooranorimi, G. Claure, W. Suaris, and A. Nanni, "Bondslip effect in flexural behavior of GFRP RC slabs," Composite Structures, vol. 193, pp. 80-86, 2018. 